\title{
Tramadol withdrawal in a neonate: how should it be treated?
}

\author{
C. Willaschek • E. Wolter $\cdot$ R. Buchhorn
}

Received: 8 February 2009 / Accepted: 10 February 2009 / Published online: 4 March 2009

(C) Springer-Verlag 2009

\section{Dear Sir,}

Our case of tramadol withdrawal in a neonate recently published in this journal [1] raised a comment which we read with great interest and pleasure. The commentators draw attention to the high inter-individual variability in tramadol elimination clearance, which, in addition to metabolic maturation by postmenstrual age, depends on cytochrome P450 (CYP) 2D6 polymorphisms. In relation to breast-feeding the newborn, they further discuss the combined effect of maternal CYP2D6 activity and maternal dose as variables affecting the central-nervous-system symptoms of the newborn, which can manifest either as depression or withdrawal. This comment needs to be considered fully [2].

Compared to the vast experience with methadone withdrawal, there is little clinical experience with treating tramadol withdrawal syndrome in a neonate. From single reports, we learn that symptoms caused by tramadol withdrawal among adults may relate not only to the drug's opioid properties but also to its non-opioid properties such as 5-HT reuptake-blocking effects; these may not be

C. Willaschek $(\bowtie) \cdot$ R. Buchhorn

Klinik für Kinder- und Jugendmedizin, Caritaskrankenhaus,

Uhlandstr. 7,

97980 Bad Mergentheim, Germany

e-mail: christian.willaschek@ckbm.de

E. Wolter

Klinik für Anästhesie und Intensivmedizin, Caritaskrankenhaus,

Uhlandstr. 7,

97980 Bad Mergentheim, Germany completely resolved by substitution of a pure opioid [3, 4]. Therefore in our case there was some uncertainty about the treatment. A pure M1 agonist probably would not have addressed non-opioid symptoms. The other reported case of tramadol withdrawal in a neonate was treated successfully with diazepam and phenobarbital, which have no effects on $\mu$-receptors. Treatment with tramadol itself might have been an option. But considering that the indication was withdrawal syndrome, this would have meant off-label treatment. Clonidin, which is used for control of withdrawal after long-term analgo-sedation with opioids, might have been an alternative. As it is often used for opioidwithdrawal syndrome in neonates, tinctura opii was our first choice. Symptom control could be achieved quickly. For these reasons, tinctura opii seems to be an option to treat this rare clinical problem.

Of course the restricted evidence from a single case observation is not definitive; there can not be a general recommendation for the use of tinctura opii. As a phytotherapeutic, it contains a standardised concentration of morphine, but the concentrations of a large number of other substances, such as papaverin and noscapin, may vary.

\section{References}

1. Willaschek C, Wolter E, Buchhorn R (2008) Tramadol withdrawal in a neonate after long-term analgesic treatment of the mother. Eur $\mathrm{J}$ Clin Pharmacol. doi:10.1007/s00228-008-0598-Z

2. Allegaert K, Ilett K, Koren G (2009) Tramadol withdrawal in a neonate: only one of the clinical presentations to be anticipated. Eur $\mathrm{J}$ Clin Pharmacol (in press)

3. Barsotti CE, Mycyk MB, Reyes J (2003) Withdrawal syndrome from tramadol hydrochloride. Am J Emerg Med 21(1):87-88

4. Grond S, Sablotzki A (2004) Clinical pharmacology of tramadol. Clin Pharmacokinet 43:879-923 